\title{
Research on Teaching Reform of Hydraulic and Pneumatic Transmission Based on OBE
}

\author{
Liping $\mathrm{Xu}^{1, \mathrm{a}}$, Liujin $\mathrm{Cai}^{1, \mathrm{~b}^{*}}$ and Xiaoqing $\mathrm{Nan}^{1, \mathrm{c}}$ \\ ${ }^{1}$ School of Mechatronic Engineering, Henan University of Science and Technology, Luoyang, \\ 471003, China \\ axlpzz@163.com, byycailj@163.com, c1045774761@qq.com \\ *The corresponding author
}

Keywords: OBE; AME Sim; Hydraulic and pneumatic transmission; Teaching reform

\begin{abstract}
For the strong theoretical, practical and applied characteristics of "Hydraulic and Pneumatic Transmission", the traditional teaching methods of the course has been facing difficulties which the teachers find it difficult to teach and the students feel it hard to learn for a long time. In order to improve teaching efficiency and quality of the course, the OBE method was applied in the teaching practice of the course. The method relies on AMESim software and actual engineering project to realize the combination of theory and practice, furthermore provides an open self-learning platform for students. Experimental study on the teaching of the course for two years was carried out by using equal group test method to verify the effect of OBE. The results show that the OBE mode can not only play a very good role in the course teaching and significantly improve the teaching effect, but also promote students' professional quality and the ability of independent innovation.
\end{abstract}

\section{Introduction}

The grim employment situation of the machinery leads to mechanical engineering graduates facing huge employment pressure. It is difficult to find a good job if you do not have a solid professional knowledge and skills. "Hydraulic and Pneumatic Transmission" as one of the important basic courses that mechanical engineering students must grasp, plays a fundamental role in the teaching system of the whole mechanical courses[1]. However, because of its strong theoretical, practical and applied characteristics, the teaching of this course is facing many difficulties. In the traditional theory teaching, by drawing time-consuming, PPT presentation is difficult to make complicated hydraulic circuit and hydraulic components of the working state display clearly, which lead to students uninterested and low efficiency of the teaching. In the practice teaching, students in the teaching process see less of hydraulic components and do not understand the actual working condition. This way dampen the enthusiasm of students to experiment and explore. In view of the teaching problems and difficulties, this paper studies and discusses the theory and practice teaching of "hydraulic and pneumatic transmission" with the project of "Outcomes-based Education" OBE education mode and AMESim software[2,3].

\section{Theory Teaching Reform and Teaching Case of "Hydraulic and Pneumatic Transmission"}

Introduction of OBE. Based on the mode of OBE, educators must have a clear idea of the ability and the level of the graduates and seek to design an appropriate educational structure to ensure that students achieve the desired goals[4]. The course of "hydraulic and pneumatic transmission" must be centered on the students' knowledge, ability and quality. It explores the coordination and cooperation between different courses. OBE as the guide, teaching reform methods and research, to carry out the integration of production and education, to carry out the enterprise standard of the project construction project, to explore the contents of the "to" the student oriented establishes the curriculum standards[5,6]. 
The Combination Methods of OBE and "Hydraulic and Pneumatic Transmission" Theory Teaching. Graduates' professional and technical ability is very important in the society nowadays, so in the teaching process we should make students be the main part of teaching, the student to obtain ability as the final result[7,8]. So the course training goal of "Hydraulic and Pneumatic Transmission" should be targeted for improving the professional quality of hydraulic and pneumatic, in both the basic knowledge of hydraulic and pneumatic focus on training students' ability to adapt to the future job at the same time, emphasize application skill training. The traditional course of "Hydraulic and Pneumatic Transmission" is just for the teaching material, there is no corresponding software for teaching, so both teachers and students have difficulty in the teaching process[9]. Using AMESim software for teaching in the course of the hydraulic and pneumatic transmission, not only could put the materials on the complex hydraulic circuit and relationship of intuitive and concrete, but also could display the engineering practice of the control system of vividly in front of students, in the interactive learning and experiments to increase student's perceptual knowledge of the control system and cultivate their interest in this course[10,11].

Teaching Case of the Methods. The following combines of OBE engineering education mode with practical application value of the sugarcane harvester cutting lifting system as an example, introduce the AMESim in the application of the theory of the hydraulic and pneumatic transmission course. Fig. 1 is the cutting lifting hydraulic system schematic diagram, in the traditional teaching, the teacher will only through PPT broadcasting, posted on the static system schematic diagram for the teaching, students often have no way to really learning the system in a short period of time, they often only know little knowledge to deal with the final exam. Fig. 2 is the AMESim simulation schematic diagram, in the figure, the step signal " 5 " is used to represent the system working set of the knife dish the height distance, namely the sugarcane harvester cutter reservation when cutting sugarcane stubble height, random signal " 12 " is used for simulating the ground ups and downs, according to the sugar cane of the actual working condition, set up the device parameters, the PID parameters, students can experience different parameters in this process have any effect on the response curve.

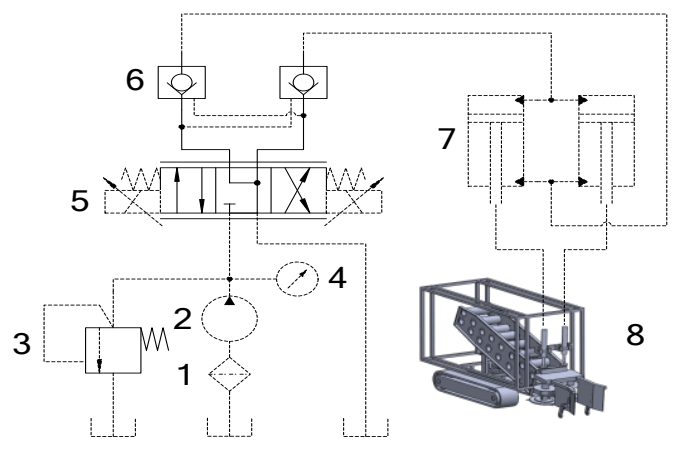

Figure 1. Schematic diagram of hydraulic system of cutting

1 Filter; 2 Quantitative hydraulic pump; 3 Relief valve; 4 Hydraulic Gauge; 5 Proportional directional control valve; 6 Hydraulic lock; 7 hydraulic cylinder; 8 Sugarcane harvester model 


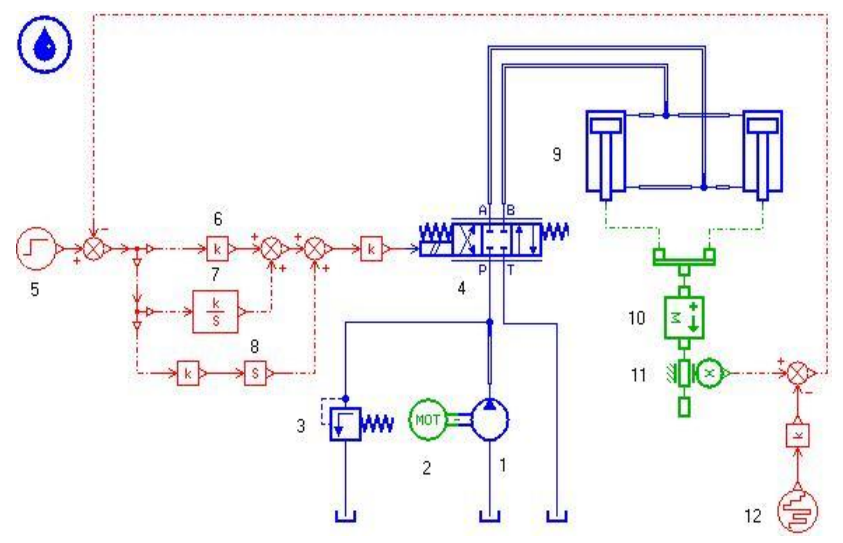

Figure 2. AMESim simulation schematic

1 Hydraulic pump; 2 Prime mover; 3 Relief valve; 4 Proportional directional control valve; 5 Step signal; 6 Ratio constant; 7 Integral constant; 8 Differential constant; 9 Hydraulic cylinder; 10 Mass block; 11 Displacement transducer; 12 random signal

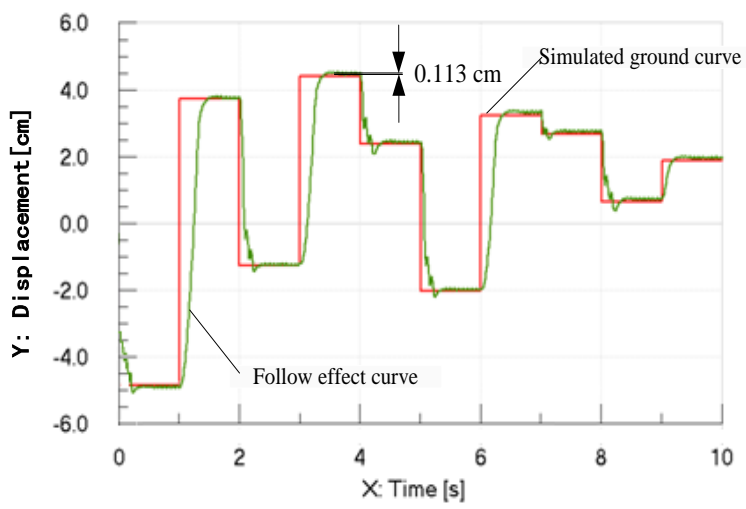

(a) Cut stubble setting height is $0 \mathrm{~mm}$

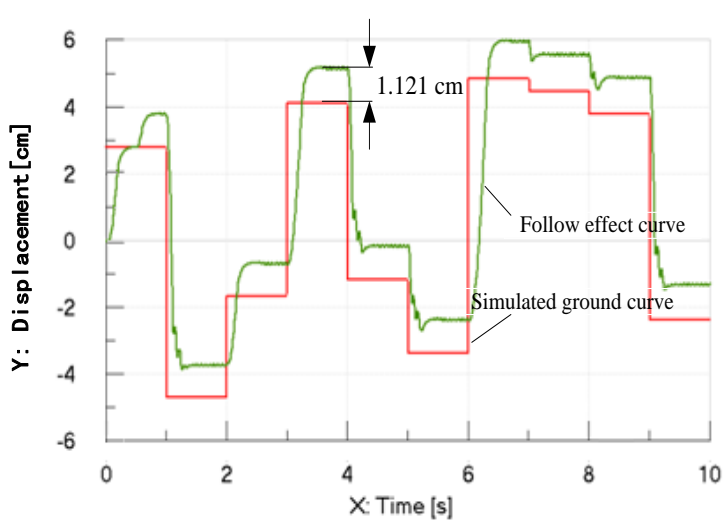

(b) Cut stubble height is set to $10 \mathrm{~mm}$

Figure 3. Random simulation of ground response effect curve

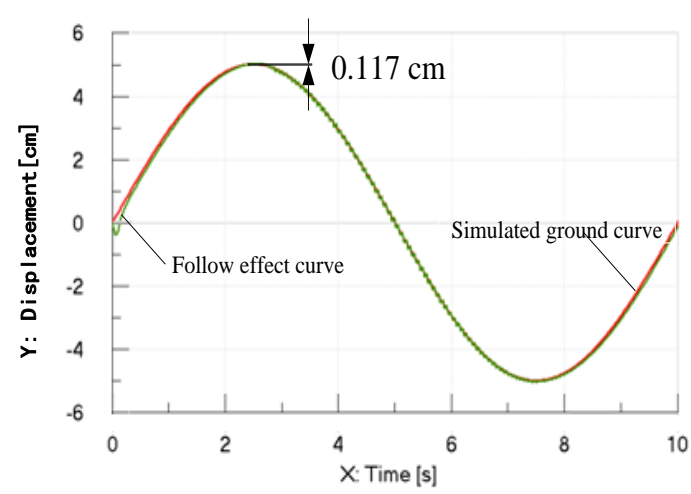

(a) Cut stubble setting height is $0 \mathrm{~mm}$

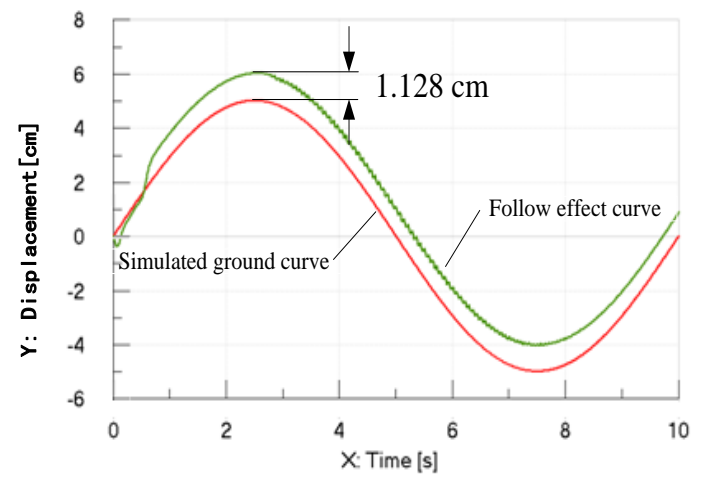

(b) Cut stubble height is set to $10 \mathrm{~mm}$

Figure 4. Sine simulation ground response effect curve

The final PID parameters are set as follows: the proportion coefficient is 300 , the integral coefficient is 16, and the differential coefficient is 5. Fig. 3 and Fig. 4 show the response of the system to simulate the random signal and the sine signal respectively. Figure (a) and (b) show respectively the system's simulation of ground conditions following profiling of the stubble height are set $0 \mathrm{~cm}$ and $1 \mathrm{~cm}$. It can be seen from the figure, the system can be well used to profile on the 
ground and follow ups and downs. In the response of the ground response of random signals, the same phenomenon of step response can be seen, and the rise time is slightly slower than that fall time which is slightly over time. In the response of the sinusoidal signal to the ground, the height of the cutting stubble is zero, the two curves are basically coincident and the good following characteristics are verified. The accuracy of the system is less than $2 \mathrm{~mm}$. It can be seen from the figure that cutting stubble height is set $0 \mathrm{~cm}$ and $1 \mathrm{~cm}$ and the simulation error is $1.13 \mathrm{~mm}, 1.21 \mathrm{~mm}$, $1.17 \mathrm{~mm}, 1.128 \mathrm{~mm}$ respectively. The error is not greater than $2 \mathrm{~mm}$, so the control accuracy can meet the design requirements.

\section{Experimental Teaching Reform and Teaching Case of "Hydraulic and Pneumatic Transmission"}

As an important basic course of engineering major, the experiment of "hydraulic and pneumatic transmission" involves a wide range of students, a large number of students and more batches of teaching process, all colleges and universities have practical problems such as lack of experimental devices, so they basically turn the test of learning effect of students into the experimental report writing, and even lead students to copy each experimental report and experimental data after the experiment, and do not attach importance to strengthen the training of engineering cognitive and engineering consciousness but pay attention to rote handouts content, often appear such bad phenomenon that high scores Students won't experiment operation and have no concept of hydraulic engineering.

After debugging through the AMESim software, the students enter the laboratory. Experimental instructions only give the experimental content, purpose and the general principles that students must be based on the experimental content, purpose and requirements of components to set up experimental platform. Through the observation of the experimental results of the real system, the analysis of experimental results, the students ultimately write the experimental report. OBE oriented assessment mode should strengthen the student assessment efforts in the whole process of experiment teaching, students before the experiment preview as assessment test whether students with problems in laboratory, whether the experiment will face the operational points of the preliminary preview to Students in the process of the actual performance of the examination points to encourage students to complete the experiment seriously in the course of the experiment, and actively explore with teachers, and strive to solve the problem and innovation to complete the experiment, the experimental project after the end of the project awareness and awareness. According to the assessment of the overall train of thought, adhere to the student's learning results assessment is not based on experimental reports, not to test the results of a test, adhere to the student experimental preparation, experimental process, the experimental results of three parts.

A case of sugarcane harvester cutting platform lifting system, AMESim software debugging of the system,students have been preliminary understanding in class.With their own opinions and questions, students build electro-hydraulic proportional position control system in the FESTO electro-hydraulic control test bench and make a simple swing arm type terrain detection device. Electric control system of the electro-hydraulic proportional control system includes a computer controller, power drive circuit board, circuit board, angular displacement sensor. And the hydraulic system comprises a hydraulic pump station, three position four way proportional reversing valve, overflow valve and single rod hydraulic cylinder components as shown in Fig. 5. Students can analysis of the causes of different results by testing the system and AMESim software debugging results contrast. Take the actual project as an example, so that students can really understand the sugarcane harvester cutting platform lifting system. 


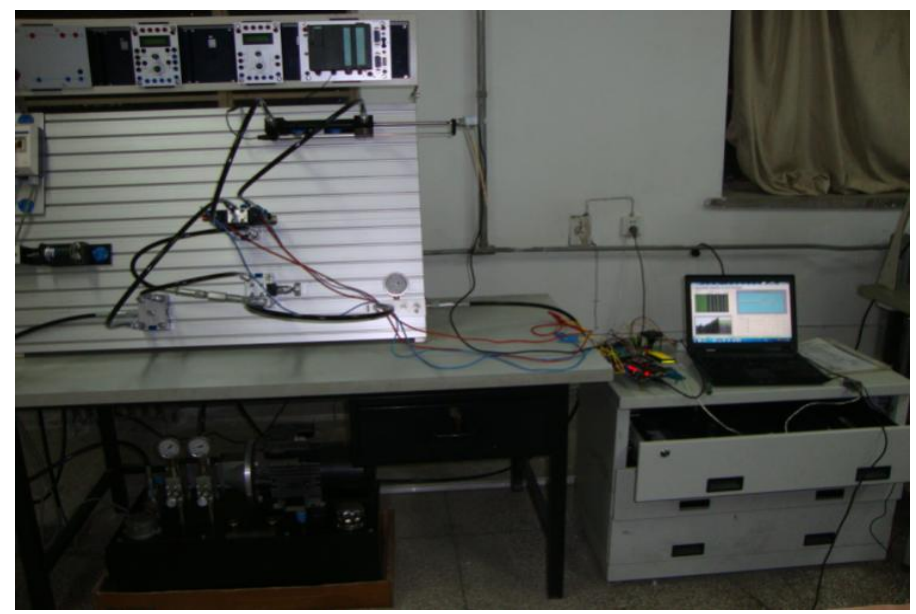

Figure 5. Experimental device

\section{Analysis and Effect Evaluation of Teaching Experiment}

Test Object. In order to verify the effect of "learning outcomes" OBE engineering education model and AMESim software in "hydraulic and pneumatic transmission" course, we have selected two parallel classes for 2 consecutive years in the Department of mechanical and electronic engineering in a university, respectively: Mechanical and electrical class 121, class 122, class 131, class 132 . The ability and grade of the students in the grade is same. class 1 as the experimental class, class 2 of the same grade as the control class, the students of the 4 classes are compared in Table 1.

Table 1 Contrast between experimental class and control class students

\begin{tabular}{ccccc}
\hline & \multicolumn{2}{c}{ Test class } & \multicolumn{2}{c}{ Control class } \\
\hline Class & 121 & 131 & 122 & 132 \\
Number & 32 & 35 & 31 & 33 \\
Grade point average & 3.56 & 3.51 & 3.54 & 3.55 \\
\hline
\end{tabular}

Test Method and Process. The teaching experiment using equal groups experimental method, namely, in the same grade of two roughly the same class, using different teaching process comparing the teaching, and through the way of curriculum assessment to compare and evaluate the teaching effect of the different teaching process. In comparative classes, using the conventional hydraulic and pneumatic transmission. Teaching methods, such as theory teaching, experiment assessment, course assessment, and in experimental class, on the basis of comparative class's teaching method, increasing OBE engineering education mode of "Learning Outcomes" and uniting AMESim software teaching model. First of all, experimental class and comparative classes is taught centralized theory teaching(the instructor and teaching content are the same), the experimental class is used the OBE engineering education mode, Then they are scheduled to do the AMESim simulation experiment, finally experimental skills assessment and curriculum assessment for the experimental class and that in comparative classes in the same time.

Analysis and Evaluation of Test Results. In the course of teaching experiment, we find that in the real laboratory, the students in the experimental class are easy to handle both the operation of the experimental equipment and the details of the experiment, and the experimental efficiency and proficiency are obviously higher than that of the students in the control class. Thus, after the early bedding for AMESim simulation experiment, the students in the experimental class have more stronger hands-on ability, lower failure rate and repetition rate and higher average score than those in the control class. Through the curriculum assessment, we also find that the comprehensive performance of the experimental class of the same grade are significantly higher than that of the 
control class, this shows that the students in the experimental class have a better grasp of the course knowledge. The details are shown in Table 2. This shows that AMESim simulation experiment as a warm-up training before the real experiment combined with the "learning output" OBE engineering education mode can not only exercise the students' experimental skills but also increase the students' mastery of the course knowledge, and also can significantly improve the professional quality of students.

Table 2 Comparison between the test class and the control class

\begin{tabular}{|c|c|c|c|c|c|}
\hline & & \multicolumn{2}{|c|}{ Test class } & \multicolumn{2}{|c|}{ Control class } \\
\hline \multicolumn{2}{|c|}{ Class } & 121 & 131 & 122 & 132 \\
\hline \multicolumn{2}{|c|}{$\begin{array}{l}\text { Number of experimental } \\
\text { failures }\end{array}$} & 2 & 3 & 9 & 10 \\
\hline \multicolumn{2}{|c|}{ failure rate } & $6.45 \%$ & $8.82 \%$ & $30.00 \%$ & $30.30 \%$ \\
\hline \multirow{2}{*}{\multicolumn{2}{|c|}{$\begin{array}{c}\text { Experimental average score } \\
\text { Comprehensive average } \\
\text { score }\end{array}$}} & 87.67 & 89.20 & 79.98 & 80.78 \\
\hline & & 83.69 & 84.13 & 77.38 & 78.50 \\
\hline \multirow{2}{*}{$\begin{array}{l}\text { Significant } \\
\text { T test }\end{array}$} & $\begin{array}{l}\text { The value of } \\
\mathrm{P}^{*}\end{array}$ & $\times$ & $x$ & 0.002 & 0.005 \\
\hline & $\begin{array}{l}\text { Significant } \\
\text { difference }\end{array}$ & $x$ & $x$ & $\begin{array}{l}\text { Significant } \\
\text { difference }\end{array}$ & $\begin{array}{l}\text { Significant } \\
\text { difference }\end{array}$ \\
\hline
\end{tabular}

*: $\mathrm{P}<0.05$ represent that the control class and test scores were significantly different.

\section{Conclusion}

By comparing the teaching, it can be seen that the use of OBE education model combined with AMESim software teaching methods can better stimulate students' hands-on and practical ability, and promote the improvement of students' awareness of innovation. The teaching methods of OBE mode combined with AMESim software adhere to the student oriented, if the students are required by the engineer's standard, it can make the students more handy in the recruitment of enterprises. We will adhere to educational innovation, promote the reform and innovation of engineering education, and promote engineering education of our country from big power into strong power.

\section{Acknowledgement}

The authors gratefully acknowledge the superior course of Henan University of Science and Technology for financial support of this research work(No. 2012N-007).

\section{References}

[1] F.L Xu, Y.M Chen: hydraulic and pneumatic transmission (China Machine Press, China 2007)

[2] P.H Gu, W.L Hu and P Lin: Research in Higher Education of Engineering, (2014)No.1, p.27.

[3] Y.G Yang, B Meng and W.N Wang: Research in Higher Education of Engineering, (2015)No.6, p.24.

[4] Y Song, S Hu and Z.Y Yu: Experimental Technology and Management, Vol. 33 (2016)No.2, p.4.

[5] X.Q Chen, G.L Dai: Journal of Zhejiang University of Technology, Vol. 14 (2015)No.4, p.464.

[6] Information on http:// en. Wikipedia. Org/wiki/Outcome-based-education \# United states.

[7] B Liu, M Zhou and C.S Tong: Experimental Technology and Management, Vol. 33 (2016)No.3, 
p.197.

[8] Q Feng: journal of Anhui Polytechnic University, Vol. 31 (2016)No.3, p.81.

[9] R Liu, L.L Wan and F Yuan: China Education of Light Industry, (2016)No.1, p.15.

[10]T.Y Han, Z.M Liu and Y.S Hu: Experimental Technology and Management, Vol. 33 (2016)No.5, p.174.

[11]C.Y Zhou, Y Liu and D.W Yao: Experimental Technology and Management, Vol. 33 (2016)No.10, p.19. 